\title{
Sustained Activity in the Medial Wall during Working Memory Delays
}

\author{
Laurent Petit, Susan M. Courtney, Leslie G. Ungerleider, and James V. Haxby \\ Laboratory of Brain and Cognition, National Institute of Mental Health, Bethesda, Maryland 20892-1366
}

\begin{abstract}
We have taken advantage of the temporal resolution afforded by functional magnetic resonance imaging (fMRI) to investigate the role played by medial wall areas in humans during working memory tasks. We demarcated the medial motor areas activated during simple manual movement, namely the supplementary motor area (SMA) and the cingulate motor area (CMA), and those activated during visually guided saccadic eye movements, namely the supplementary eye field (SEF). We determined the location of sustained activity over working memory delays in the medial wall in relation to these functional landmarks during both spatial and face working memory tasks. We identified two distinct areas, namely the pre-SMA and the caudal part of the anterior cingulate cortex (caudal-AC), that showed similar sustained activity during both spatial and face
\end{abstract}

Sustained neural activity during the delay period of delayed response tasks is generally interpreted as the neural basis of working memory, underlying the ability to hold information about a stimulus on-line over a short period of time. With functional magnetic resonance imaging (fMRI), it is possible to identify regions that demonstrate sustained activity during working memory delays in humans and distinguish them from those regions that participate in other components of working memory task performance. For example, we have shown that fMRI can distinguish sustained, memory-related activity in prefrontal cortex during a face working memory task from transient, perception-related activity in posterior extrastriate cortex (Cohen et al., 1997; Courtney et al., 1997). In a related study, we have shown that sustained activity in the superior frontal sulcus during a spatial working memory task can be distinguished from activity related to oculomotor control in the adjacent frontal eye field (Courtney et al., 1998b).

Previous brain imaging studies have described activation of various cortical regions (e.g., prefrontal, parietal, and occipitotemporal regions) during working memory tasks, indicating that this mnemonic function is subserved by a large-scale distributed system (for review, see Owen, 1997; Courtney et al., 1998a; D'Esposito et al., 1998). Activation in medial frontal regions,

\footnotetext{
Received April 3, 1998; revised Aug. 21, 1998; accepted Sept. 3, 1998.

We thank Elizabeth Hoffman and Jennifer Schouten for help with subject recruitment, scheduling, and training, and the staff of the National Institutes of Health in vivo NMR center for assistance with MR scanning. We also thank Michael S. Beauchamp for assistance with data analysis.

Correspondence should be addressed to Dr. Laurent Petit, Laboratory of Brain and Cognition, National Institute of Mental Health, Building 10, Room 4C104, 10 Center Drive, Bethesda, MD 20892-1366.

Reprint requests should be addressed to Dr. James V. Haxby, Laboratory of Brain and Cognition, National Institute of Mental Health, Building 10, Room 4C104, 10 Center Drive, Bethesda, MD 20892-1366.

Copyright (C) 1998 Society for Neuroscience $\quad 0270-6474 / 98 / 189429-09 \$ 05.00 / 0$
}

working memory delays. These areas were distinct from and anterior to the SMA, CMA, and SEF. Both the pre-SMA and caudal-AC activation were identified by a contrast between sustained activity during working memory delays as compared with sustained activity during control delays in which subjects were waiting for a cue to make a simple manual motor response. Thus, the present findings suggest that sustained activity during working memory delays in both the pre-SMA and caudal-AC does not reflect simple motor preparation but rather a state of preparedness for selecting a motor response based on the information held on-line.

Key words: human; working memory; fMRl; supplementary motor area; pre-SMA; supplementary eye field; anterior cingulum

namely the supplementary motor area (SMA) and the anterior cingulate cortex (AC), has also been described consistently in both positron emission tomography (PET) and fMRI studies of working memory (see Table 3 ). In these previous studies, however, sustained, memory delay-related activity was not distinguished from the activity related to other working memory task components. These medial activations generally have been interpreted to reflect the motor output component of the task, such as the preparation for a manual or verbal response. Consistent with this interpretation, Picard and Strick (1996) have distinguished multiple motor areas in the medial wall. They suggested that the SMA in the dorsomedial frontal cortex can be subdivided further into the SMA-proper (or SMA), which subserves the basic spatial and temporal organization of movement, and a more anterior region called the pre-SMA, which subserves additional cognitive or motor demands, such as the selection of and preparation for a motor response. In the cingulate cortex, they defined a caudal cingulate motor area (CMA) [also called the caudal cingulate zone (CCZ) by Picard and Strick (1996)], which subserves simple motor functions and a larger anterior cingulate area [also called the rostral cingulate zone (RCZ) by Picard and Strick (1996)], which subserves more complex motor functions. In an earlier review of the AC, Devinsky et al. (1995) emphasized the role played by this area in response selection and attention to action.

The aim of the present study was to characterize the role played by these medial frontal areas in working memory tasks. We divided activations in both spatial and face working memory tasks into three components, namely transient activity related to visual perception, sustained activity over memory delays, and transient activity related to the manual motor response after delays. This third component allowed us to localize the medial motor areas activated during simple manual movement, namely the SMA and CMA. Subjects also performed a visually guided saccade task 


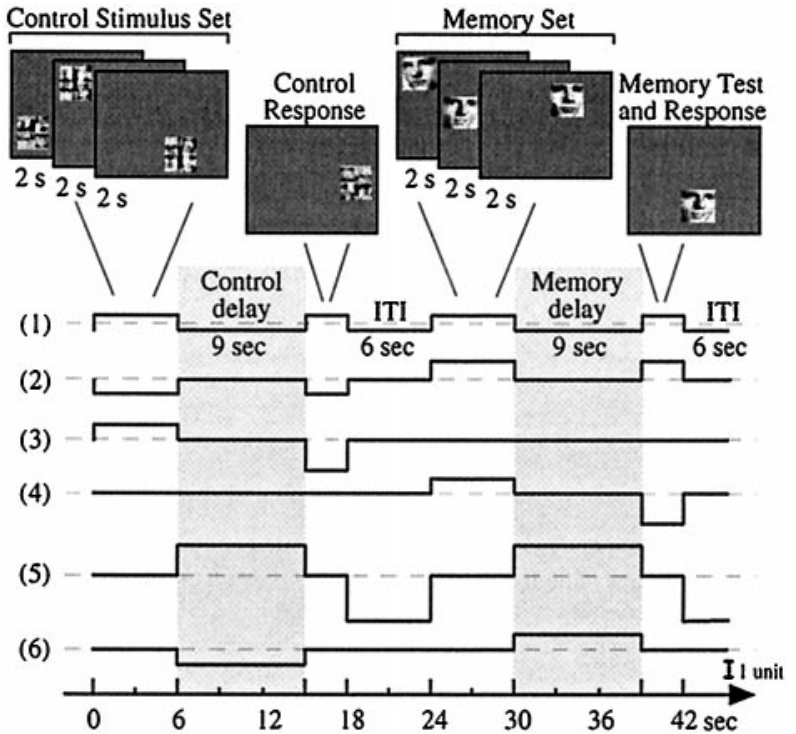

Figure 1. Working memory task diagram and description of the contrasts used for the multiple regression analysis. The contrasts made between task components are (1) visual stimulation versus no visual stimulation, (2) memory stimuli versus control stimuli, (3) the control stimulus set versus the control response, (4) the memory stimulus set versus the test stimulus and response, (5) delays during anticipation of response versus intertrial intervals, and (6) the memory delays versus the control delays (for details, see Materials and Methods) (adapted from Courtney et al., 1998b).

that allowed us to identify the location of a third medial motor area, namely the supplementary eye field (SEF). Thus, the SMA, CMA, and SEF constituted three functional landmarks in each subject. We investigated the location of sustained activity over working memory delays in the medial wall in relation to these landmarks. We contrasted sustained, memory-related activity to sustained activity related to preparation to make a manual motor response in a control task that had no memory component. The sustained activity during memory delays, therefore, could not be attributed to simple motor preparation, but rather should reflect either a state of preparedness to select a response at the end of the delay or the maintenance of an active representation of visual stimuli in working memory. We predicted that the location of sustained activity during working memory delays would lie within the pre-SMA or AC or both because of their presumed role in the more cognitive aspects of motor tasks.

Parts of this paper have been published previously in abstract form (Petit et al., 1997b).

\section{MATERIALS AND METHODS}

Subjects. Twelve healthy right-handed volunteers (mean age $27.8 \pm 2.9$ years) participated in this study. All were free of neurological or psychiatric illness, and there were no abnormalities on their structural magnetic resonance images. All subjects gave written informed consent.

Task design. In seven subjects (S6-S12), fMRI studies were conducted during performance of spatial and face working memory tasks. In five other subjects (S1-S5), fMRI studies were conducted during performance of spatial working memory and saccadic eye movement tasks. In the spatial and face working memory tasks (Fig. 1), subjects saw a series of three faces, each presented for $2 \mathrm{sec}$ in a different location on the screen, followed by a $9 \mathrm{sec}$ memory delay. After the delay, a single test face appeared in some location on the screen for $3 \mathrm{sec}$, followed by a $6 \mathrm{sec}$ intertrial interval. For the spatial working memory task, subjects were instructed to remember the locations of the three faces in the memory set, independent of the identities of the faces used to mark those locations. They indicated with a left or right button press whether the test

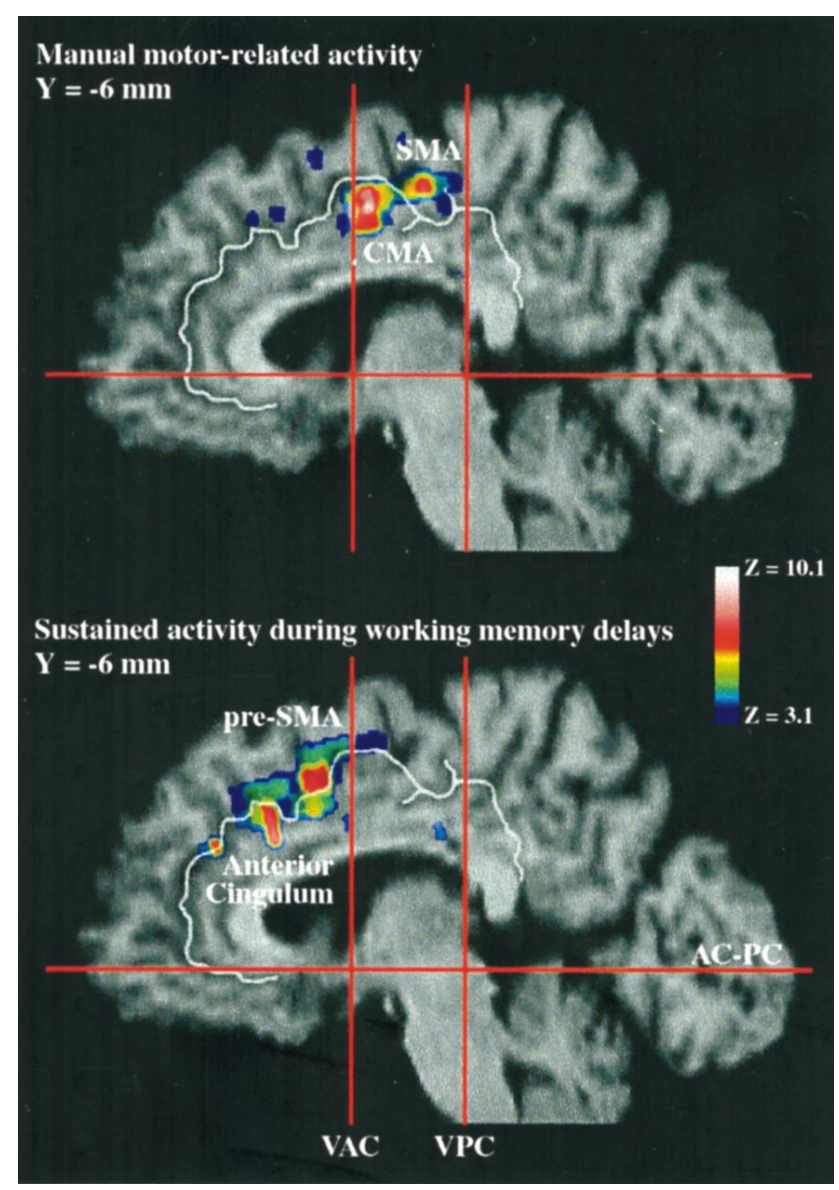

Figure 2. Color-coded $Z$-score map illustrating significant manual motor-related activity (top) (Fig. 1, regressor 3) and sustained activity during face working memory delays (bottom) (Fig. 1, regressor 6) in a single subject (S11), shown overlaid onto a Talairach normalized anatomical MR sagittal image $(Y=-6 \mathrm{~mm})$ for that subject with the cingulate sulcus shown in white. Note that the superior frontal and cingulate foci are anatomically distinct for both motor-related (top) and sustained (bottom) activity. $A C-P C$, Bicommissural plane; $V A C$ and $V P C$, vertical planes passing through the anterior and posterior commissures, respectively.

location was the same as one of the three locations presented in the memory set. For the face memory task, subjects were instructed to remember the identities of the three faces in the memory set, regardless of the location in which the face appeared. They indicated whether the test face was the same as one of the three faces seen in the memory set. Both working memory tasks used the same stimuli and were equated for difficulty. For the sensorimotor control task, scrambled faces appeared in the same sequence as that used for the working memory tasks. When the fourth scrambled picture appeared after the delay, subjects pressed both buttons. Working memory items alternated with sensorimotor control items. For both the control and working memory tasks, subjects were instructed to look directly at each picture as it appeared and to avoid moving their eyes during delay periods.

In the eye movement task, subjects executed horizontal saccadic eye movements toward a visual dot. The dot appeared first at the primary central eye position for $500 \mathrm{msec}$ and then jumped randomly to different eccentric positions on the horizontal axis with a frequency of $2 \mathrm{~Hz}$. The number of left and right saccadic eye movements was equated, with an average amplitude of $12^{\circ}$ in both directions (range, $5-20^{\circ}$ ). The visual dot size was $0.4^{\circ}$. Rest was used as the eye movement control task in which subjects were asked to keep their eyes open and avoid moving their eyes in total darkness, without any visual cue.

Visual stimuli were generated by a Power Macintosh computer (Apple, Cupertino, CA) using SuperLab software (Cedrus, Wheaton, MD) (Haxby et al., 1993) and were projected with a magnetically shielded LCD video projector (Sharp, Mahwah, NJ) onto a translucent screen 
Table 1. Talairach coordinates in the medial superior frontal cortex

\begin{tabular}{|c|c|c|c|c|c|c|c|c|c|}
\hline & \multicolumn{3}{|c|}{ Motor activity } & \multicolumn{3}{|c|}{ Sustained activity } & \multicolumn{3}{|c|}{ Saccadic activity } \\
\hline & $\mathrm{X}$ & $\mathrm{Y}$ & $\mathrm{Z}$ & $\mathrm{X}$ & $\mathrm{Y}$ & $\mathrm{Z}$ & $\mathrm{X}$ & $\mathrm{Y}$ & $\mathrm{Z}$ \\
\hline S1 & 3 & -10 & 52 & -2 & $7 * *$ & 55 & -6 & $-8^{\dagger \dagger}$ & 60 \\
\hline $\mathrm{S} 2$ & -3 & -5 & 53 & 5 & $2 *$ & 62 & 11 & $-2^{\dagger}$ & 64 \\
\hline S3 & 0 & -11 & 49 & -2 & $14^{* *}$ & 44 & -3 & $-1^{\dagger \dagger}$ & 50 \\
\hline S4 & 2 & -12 & 57 & -4 & $8^{* *}$ & 54 & 3 & $-3^{\dagger \dagger}$ & 58 \\
\hline S5 & 3 & -13 & 47 & -8 & $-5^{* *}$ & 54 & -8 & $-14^{\dagger \dagger}$ & 65 \\
\hline Mean \pm SD & $1 \pm 2$ & $-10 \pm 3$ & $52 \pm 4$ & $-2 \pm 5$ & $5 \pm 7$ & $54 \pm 6$ & $0 \pm 8$ & $-6 \pm 6$ & $60 \pm 6$ \\
\hline \multicolumn{10}{|c|}{ Spatial working memory study } \\
\hline S6 & 0 & -15 & 46 & 1 & $4^{* *}$ & 57 & & & \\
\hline S7 & 3 & -14 & 49 & 0 & $-1^{* *}$ & 54 & & & \\
\hline S8 & 2 & -9 & 49 & 0 & $11^{* *}$ & 51 & & & \\
\hline S9 & -1 & -15 & 49 & -5 & $18^{* *}$ & 43 & & & \\
\hline S10 & 0 & -17 & 54 & 2 & $16^{* *}$ & 46 & & & \\
\hline S11 & 2 & -11 & 52 & -3 & $4^{* *}$ & 53 & & & \\
\hline $\mathrm{S} 12$ & -2 & -16 & 48 & 1 & $10^{* *}$ & 46 & & & \\
\hline Mean (SD) & $0 \pm 2$ & $-14 \pm 3$ & $50 \pm 2$ & $-1 \pm 3$ & $9 \pm 7$ & $50 \pm 5$ & & & \\
\hline \multicolumn{10}{|c|}{ Face working memory study } \\
\hline S6 & 2 & -13 & 50 & -1 & $5^{* *}$ & 55 & & & \\
\hline S7 & 2 & -18 & 48 & 0 & $1^{* *}$ & 54 & & & \\
\hline S8 & 2 & -12 & 47 & 0 & $15^{* *}$ & 45 & & & \\
\hline S9 & 1 & -18 & 51 & 1 & $6^{* *}$ & 48 & & & \\
\hline S10 & 2 & -10 & 51 & -1 & $11^{* *}$ & 55 & & & \\
\hline $\mathrm{S} 11$ & 0 & -13 & 51 & 1 & $10 * *$ & 46 & & & \\
\hline $\mathrm{S} 12$ & -5 & -15 & 54 & -2 & $7 * *$ & 43 & & & \\
\hline Mean (SD) & $1 \pm 3$ & $-14 \pm 3$ & $50 \pm 2$ & $0 \pm 1$ & $8 \pm 5$ & $50 \pm 5$ & & & \\
\hline
\end{tabular}

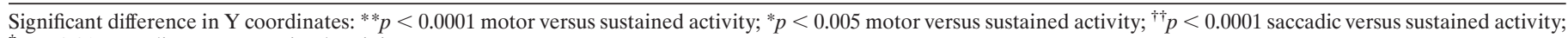
${ }^{\dagger} p<0.01$ saccadic versus sustained activity.

placed at the feet of the subject. The subject was able to see the screen by the use of a mirror system.

Imaging procedure. All imaging used a 1.5 Tesla General Electric Signa magnet (Milwaukee, WI) with a standard head coil. Interleaved multislice gradient echo planar imaging was used to produce $22-26$ contiguous, 5- or 6-mm-thick axial slices covering the entire brain [field of view $=24 \mathrm{~cm}$; repetition time $(\mathrm{TR})=3000 \mathrm{msec}$, echo time $(\mathrm{TE})=40$ msec; flip angle $90^{\circ}, 64 \times 64$ matrix of $3.75 \mathrm{~mm}^{2}$ voxels). Five of the seven subjects who performed both working memory tasks were studied in two different sessions, one consisting of eight series contrasting spatial working memory and sensorimotor control, and the other consisting of eight series contrasting face working memory and sensorimotor control. The two remaining subjects were studied in a single session that consisted of 12 series, 6 series contrasting the spatial working memory task and the sensorimotor control task, and six series contrasting the face working memory task and the sensorimotor control task. The five subjects who performed both the spatial working memory and eye movement tasks were studied in a single session, which consisted of six series contrasting the spatial working memory and sensorimotor control tasks and four series contrasting the saccadic eye movement and rest control tasks. The order of all tasks was counterbalanced across subjects.

For each working memory series, subjects alternated between a single working memory item and a single control item, each of which lasted 24 sec. Each working memory time series consisted of 88 scans with a total duration of $4 \mathrm{~min}, 24 \mathrm{sec}$. For each eye movement time series, subjects alternated $15 \mathrm{sec}$ of a rest control task and $15 \mathrm{sec}$ of the saccadic task. Each time series consisted of 60 scans with a total duration of 3 min. The scanner was in the acquisition mode for $12 \mathrm{sec}$ before each series to achieve steady-state transverse magnetization.

For all studies, high-resolution volume spoiled gradient recalled echo structural axial images were also acquired at the same locations as the echo planar images $\left(\mathrm{TR}=13.9 \mathrm{msec}, \mathrm{TE}=5.3 \mathrm{msec}\right.$; flip angle $\left.30^{\circ}\right)$ to provide detailed anatomical information.

Data analysis. The fMRI time series data were analyzed using multiple regression (Neter et al., 1990; Friston et al., 1995; Rencher, 1995; Clark et al., 1998; Haxby et al., 1998). For the working memory tasks, the contrasts made between task components are shown in Figure 1. All contrasts were constructed a priori so that the sum of values over the time series equaled zero, and the cross products of all pairs of contrasts were equal to zero, demonstrating orthogonality. These contrasts make it possible to obtain independent estimates of activity levels during every phase of the task. Each of the time series was convolved with a Gaussian model of the hemodynamic response to produce the six regressors used in the analysis. Multiple regression simultaneously calculates a weighting coefficient for each regressor so that the sum of all of the regressors multiplied by their weighting coefficients provides the best fit to the data.

Regressors 3 and 6 were chosen to test the hypotheses that motivated our study. Regressor 3 contrasted, during control tasks, the transient, perception-related activity evoked by the presentation of the stimulus set versus the transient, perception-related and motor-related activity evoked by the stimulus item and response after the delay. Thus, regressor 3 reflected the manual motor-related activity corresponding to the button press movement and was used to probe both SMA and CMA activation in the medial wall. Regressor 6 contrasted sustained, memory-related and motor preparation-related activity during working memory delays versus sustained, motor preparation-related activity during control delays. In other words, it reflected a state of preparation to select a response based on the information held on-line as compared with simple preparation to press both buttons. For the eye movement task, a saccadic eye movement versus rest contrast was used to probe the SEF activation in the medial wall. For each subject, $Z$-score maps and structural images were transformed into the standard stereotactic Talairach space (Talairach and Tournoux, 1988) with the three-dimensional version of SPM (Friston, 1995).

Activated voxels in the anterior medial wall were assigned to two volumes of interest (VOIs): the dorsomedial part of the superior frontal cortex and the cingulate cortex. Using the Talairach normalized structural images, this parcellation was achieved for each subject using software (Voxtool; General Electric, Buc, France) designed for brain segmentation, reconstruction of the external surfaces of both hemispheres, and the display of sections in any orientation.

The VOIs consisted of $15 \mathrm{~mm}$ of the cortex on each side of the 


\begin{tabular}{|c|c|c|c|c|c|c|}
\hline & \multicolumn{3}{|c|}{ Motor activity } & \multicolumn{3}{|c|}{ Sustained activity } \\
\hline & $\mathrm{X}$ & $\mathrm{Y}$ & $\mathrm{Z}$ & $\mathrm{X}$ & $\mathrm{Y}$ & $\mathrm{Z}$ \\
\hline S1 & 3 & -9 & 42 & 4 & $13^{* *}$ & 39 \\
\hline S2 & -2 & -4 & 38 & 5 & 5 & 36 \\
\hline S3 & -1 & -1 & 45 & 0 & $11^{* *}$ & 40 \\
\hline S4 & 3 & -2 & 41 & 4 & $21^{*}$ & 34 \\
\hline S5 & 3 & -10 & 40 & -9 & 4 & 36 \\
\hline Mean $\pm \mathrm{SD}$ & $1 \pm 3$ & $-5 \pm 4$ & $41 \pm 2$ & $1 \pm 6$ & $11 \pm 7$ & $37 \pm 2$ \\
\hline \multicolumn{7}{|c|}{ Spatial working memory study } \\
\hline S6 & -3 & -5 & 37 & -4 & $24^{* *}$ & 35 \\
\hline S7 & 5 & -5 & 41 & 4 & $10^{* *}$ & 41 \\
\hline S8 & 2 & 0 & 40 & 2 & $12^{* *}$ & 41 \\
\hline S9 & -4 & 4 & 37 & -8 & $17^{* *}$ & 37 \\
\hline S10 & -1 & -8 & 40 & 12 & $1^{*}$ & 43 \\
\hline S11 & -1 & 0 & 39 & -2 & $15^{* *}$ & 32 \\
\hline $\mathrm{S} 12$ & -1 & 0 & 32 & 3 & $26^{* *}$ & 26 \\
\hline Mean (SD) & $0 \pm 3$ & $-2 \pm 4$ & $38 \pm 3$ & $1 \pm 6$ & $15 \pm 9$ & $36 \pm 6$ \\
\hline \multicolumn{7}{|c|}{ Face working memory study } \\
\hline S6 & 2 & -17 & 41 & -8 & $24 * *$ & 34 \\
\hline S7 & 5 & -6 & 42 & 4 & $12^{* *}$ & 41 \\
\hline S8 & 2 & -8 & 41 & 0 & $18^{* *}$ & 39 \\
\hline S9 & 2 & 7 & 41 & -6 & 5 & 28 \\
\hline $\mathrm{S} 10$ & 3 & -8 & 40 & & & \\
\hline S11 & 0 & -1 & 40 & 2 & $20^{* *}$ & 33 \\
\hline $\mathrm{S} 12$ & -9 & -4 & 38 & 3 & $15^{* *}$ & 26 \\
\hline Mean (SD) & $1 \pm 5$ & $-5 \pm 7$ & $40 \pm 1$ & $-1 \pm 5$ & $16 \pm 7$ & $33 \pm 6$ \\
\hline
\end{tabular}

Significant difference in Y coordinates: ${ }^{*} p<0.0001$ motor versus sustained activity; ${ }^{*} p<0.005$ motor versus sustained activity.

interhemispheric fissure anterior to the vertical plane passing through the posterior commissure (VPC). The VOI delineating the dorsomedial part of the superior frontal gyrus extended forward to the anterior convexity (see Fig. 4, left side). Its inferior limit corresponded to the cingulate sulcus in the posterior part and to the plane $45 \mathrm{~mm}$ above the bicommissural plane in the anterior part. This inferior limit was chosen to delineate the medial part of Brodmann's area 6 that contains the SMA (Picard and Strick, 1996). The VOI delineating the cingulate gyrus encompassed the cingulate cortex from the VPC forward to the bicommissural plane for its inferior limit (see Fig. 4, left side). Its superior limit corresponded to the cingulate sulcus.

\section{RESULTS}

\section{Location of the functional landmarks (SMA, CMA, and SEF)}

All subjects showed two distinct foci of manual motor-related activity (regressor 3) in the medial frontal cortex, one in the dorsomedial part of the superior frontal cortex and the other in the cingulate cortex. Figure 2 (top) illustrates the distribution of the two foci relative to the cingulate sulcus for one subject. All subjects showed a similar distribution with a local maximum of motor-related activity in the cingulate cortex that was distinct and significantly anterior to the local maximum in the medial superior frontal cortex (mean difference $12 \mathrm{~mm} ; p<0.0005$ ).

Within the medial superior frontal cortex, $73 \%$ (median across subjects) of the cortex demonstrating motor-related activity was posterior to the vertical plane passing through the anterior commissure (VAC). Table 1 shows the Talairach coordinates of the centroid of motor-related activity for each subject. The mean coordinates of motor-related activity $(1,-13,50 ; n=19$ comparisons in 12 subjects) located it clearly in the SMA (see Fig. 4, red square), as defined recently (Picard and Strick, 1996). In the cingulate cortex, 68\% (median across subjects) of the cortex showing motor-related activity was also located posterior to the VAC. Table 2 shows the Talairach coordinates of the centroid for each subject. The mean coordinates of the cingulate motorrelated activity $(0,-4,40 ; n=19$ comparisons in 12 subjects $)$ located it in the CMA (see Fig. 4, red square), as defined recently (Picard and Strick, 1996). Figure 3 (right) illustrates the averaged evoked fMRI time series response to the button press movement in SMA and CMA during both face and spatial working memory task performances.

All subjects performing the saccadic eye movement task showed oculomotor-related activity in the dorsomedial part of the superior frontal cortex (Table 1). In this region, $79 \%$ (median across subjects) of the cortex demonstrating oculomotor activity was posterior to the VAC. Mean coordinates of this activation $(0$, $-6,60 ; n=5$ subjects) identified the location of the SEF (Fig. 4, red diamond). No oculomotor-related activity was observed in the cingulate cortex.

\section{Location of the sustained activity during working memory delays}

All subjects showed two distinct foci of sustained activity during spatial working memory delays (regressor 6) in medial frontal cortex: one in the dorsomedial part of the superior frontal cortex and the other in the cingulate cortex. Figure 2 (bottom) illustrates the distribution of the two foci relative to the cingulate sulcus for one subject. All subjects showed a similar distribution, with the local maximum of sustained activity in the cingulate cortex distinct from and significantly anterior to the one in the medial superior frontal cortex (mean difference $=13 \mathrm{~mm} ; p<0.0001$ ). 


\section{A. Face working memory}

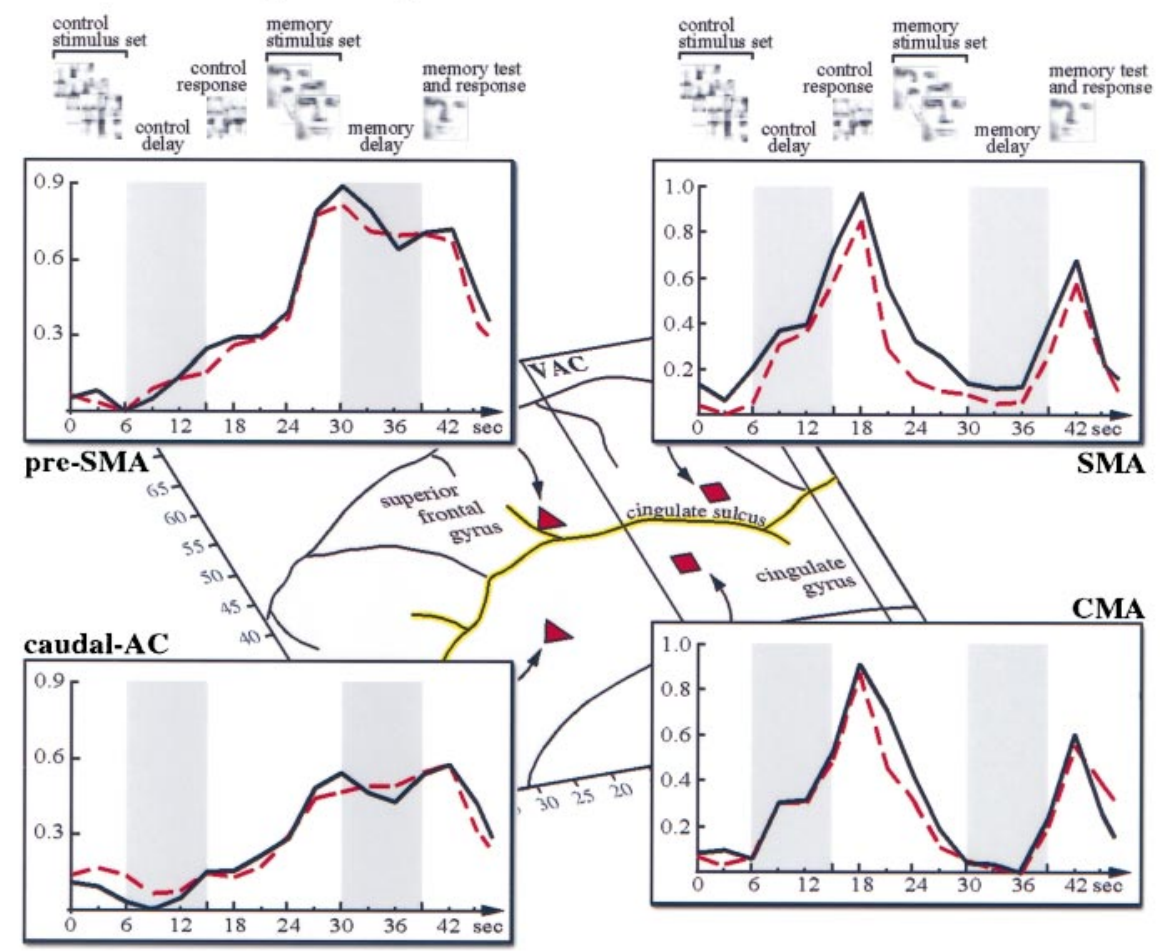

\section{B. Spatial working memory}

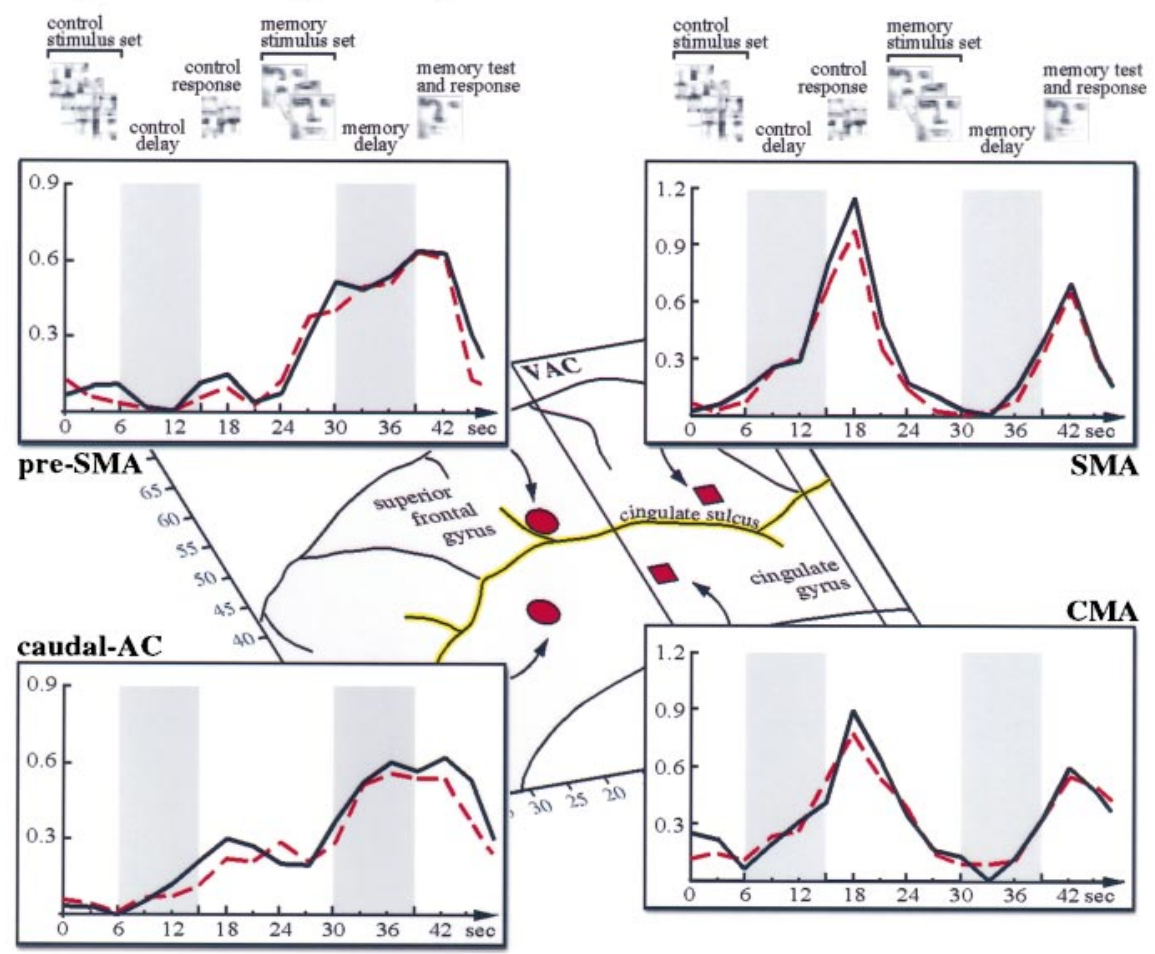

Figure 3. Plot of Talairach coordinates (in millimeters) of manual motor-related (red squares) and working memory delay-related activities during both face (top, red triangles) and spatial (bottom, red circles) working memory tasks (for details, see Tables 1,2). Time series (inset graphs) illustrate the average response (in percentage change of MR signal, solid black line) and the corresponding fitted response function (dashed red line) from regression analysis. VAC, Vertical plane passing through the anterior commissure. The region of cortex in pink brain drawings is the same as that illustrated in the right part of Figure 4.

Figure 3 (left) illustrates the averaged evoked fMRI time series response during both face and spatial working memory delays in medial frontal cortex.

In the 12 subjects who performed the spatial working memory task, $76 \%$ of the medial superior frontal cortex (median across subjects) demonstrating sustained activity was anterior to VAC. The mean coordinates $(-1,7,52)$ of the sustained activity during spatial working memory delays were located in the pre-SMA anterior to, and clearly distinct from, both the SMA and the SEF (Fig. 4, red circle). The centroid of sustained activity was signifi- 

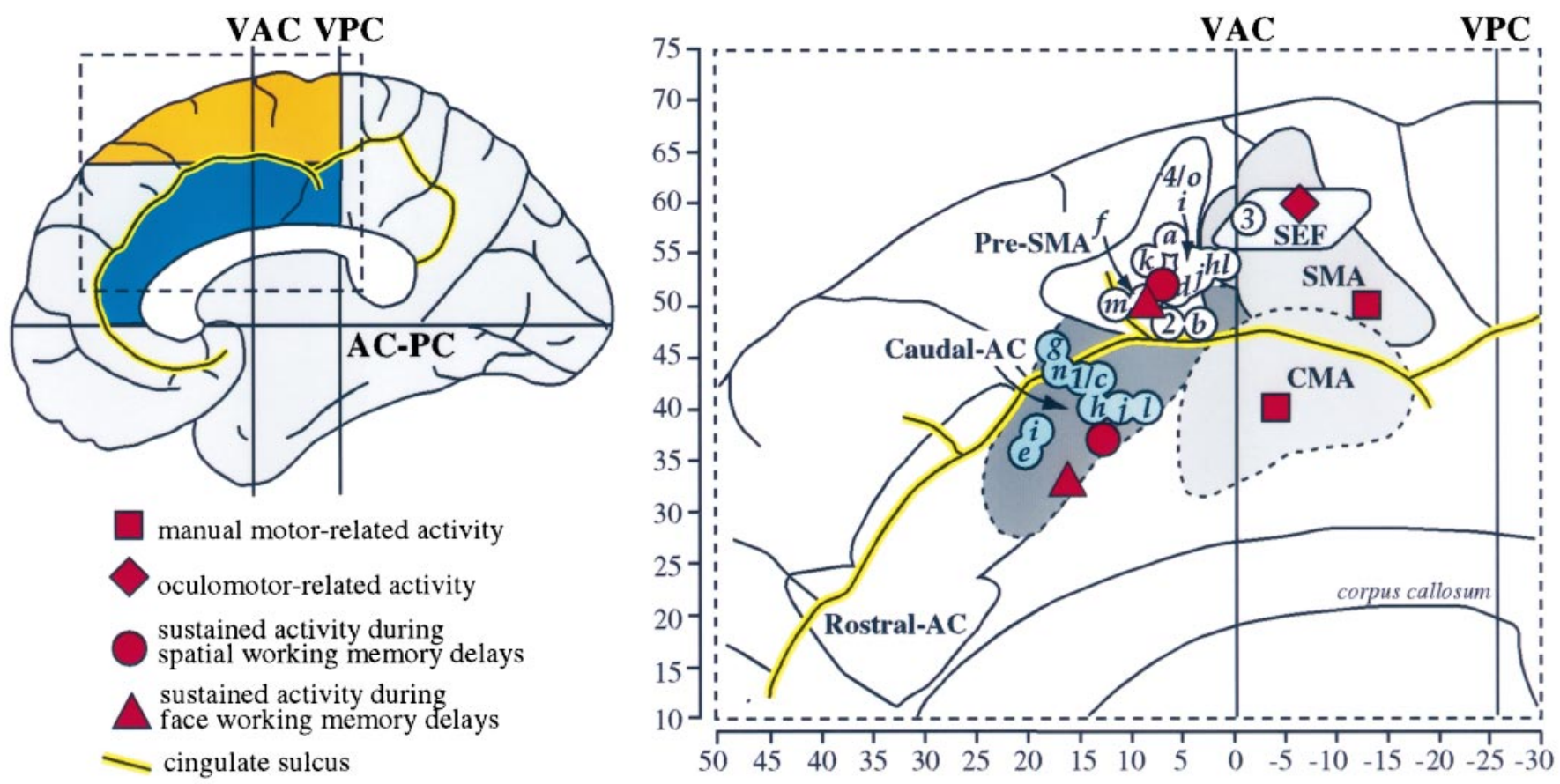

Figure 4. Left, Midsagittal view of the human brain that illustrates the VOIs defined in the present study, namely the dorsomedial part of the superior frontal cortex (orange) and the anterior and mid-cingulate cortex (dark blue) (for details, see Materials and Methods). Right, Plot of Talairach coordinates (in millimeters) of medial activations described in previous working memory studies in the medial superior frontal cortex (white filled circles) and in the cingulate cortex (blue filled circles) (for details, see Table 3). The background areas represent the boundaries of the medial motor areas according to Picard and Strick (1996), namely the supplementary motor area $(S M A)$, the cingulate motor area $(C M A)$, the pre-SMA (Pre-SMA), the caudal anterior cingulate (Caudal- $A C)$, and the rostral anterior cingulate (Rostral- $A C)$. It should be noted that this short review of the literature was not intended to survey exhaustively all studies that may have involved working memory. $A C-P C$, Bicommissural plane; $V A C$ and $V P C$, vertical planes passing through the anterior and posterior commissures, respectively.

cantly anterior to the centroid of motor-related activity [mean difference $=20 \mathrm{~mm} ; p<0.005$ in all cases (Table 1$)$ ]. In the five subjects who performed the oculomotor task, the centroid of sustained activity during spatial working memory delays was significantly anterior to the centroid of eye movement-related activity [mean difference $=11 \mathrm{~mm} ; p<0.01$ in all cases (Table 1)]. In the seven subjects who also performed the face working memory task, the spatial extents of sustained activity during spatial and face working memory were equivalent $\left(3.6 \mathrm{vs} 3.9 \mathrm{~cm}^{3}\right.$, respectively; $p>0.1$ ). Of the medial superior frontal cortex (median across subjects) demonstrating face sustained activity, $73 \%$ was anterior to the VAC. The centroid $(0,8,50 ; n=7)$ was nearly identical to the centroid found for the spatial working memory delays $(-1,9,50 ; n=7)$ and significantly anterior to the centroid of motor-related activity (Fig. 4, red triangle) [mean difference $=22 \mathrm{~mm}$ for seven subjects; $p<0.0001$ in all cases (Table 1)].

In the 12 subjects who performed the spatial working memory task, $87 \%$ of the cingulate cortex (median across subjects) demonstrating sustained activity was located anterior to the VAC. The mean coordinates $(1,13,37)$ of the cingulate sustained activity were clearly anterior to and distinct from the cingulate motor-related activity (Fig. 4, red circle) [mean difference $=17$ $\mathrm{mm} ; p<0.005$ for 10 of the 12 subjects; the two remaining subjects (S2, S5) showed the same trend, but the difference of 11 $\mathrm{mm}$ did not reach statistical significance (Table 2)]. Of the seven subjects who also performed the face working memory task, six showed significant activity in cingulate cortex. The spatial extents of sustained activity during spatial and face working memory delays did not differ significantly (0.6 vs $1.9 \mathrm{~cm}^{3}$, respectively; $p>$ 0.1 ). Of the cingulate cortex (median across six subjects) demonstrating face sustained activity, 94\% was located anterior to the VAC. Its centroid $(-1,16,33 ; n=6)$ was nearly identical to the centroid found for spatial working memory delays $(1,15,36 ; n=$ 7) and significantly anterior to the centroid of motor-related activity (Fig. 4, red triangle) [mean difference $=20 \mathrm{~mm}$ for six subjects; $p<0.0001$ in five of six subjects (Table 2)].

\section{DISCUSSION}

The present fMRI study demonstrates the existence of two distinct areas in the medial wall of human cortex, namely the pre-SMA and the caudal-AC, that show sustained activity during working memory delays as compared with sensorimotor control delays. The sustained activity during working memory delays in the pre-SMA is distinct from and anterior to the SMA and the $\mathrm{SEF}$, and the sustained activity in the caudal-AC is distinct from and anterior to the CMA. This sustained activity was similar during both spatial and face working memory delays.

\section{The reliability of the functional landmarks (SMA, CMA, and SEF)}

Two distinct foci of manual motor-related activity were located caudal to the VAC plane, one in the medial part of the superior frontal cortex and the other in the cingulate cortex, identifying the location of the SMA (or SMA-proper) and the CMA, respectively, in each subject. As illustrated in Figure 4, the mean locations of the medial manual motor-related activations in this study were within the functional boundaries delineating the hu- 


\begin{tabular}{|c|c|c|c|c|c|c|}
\hline \multirow[b]{2}{*}{ Studies } & \multicolumn{3}{|l|}{$\underline{\text { SMA }}$} & \multicolumn{3}{|c|}{ Cingulum } \\
\hline & $\mathrm{X}$ & $\mathrm{Y}$ & $\mathrm{Z}$ & $\mathrm{X}$ & $\mathrm{Y}$ & $\mathrm{Z}$ \\
\hline \multicolumn{7}{|l|}{ Spatial working memory } \\
\hline 1. Smith et al., 1995 & & & & 1 & 14 & 43 \\
\hline 2. Goldberg et al., 1996 & 0 & 6 & 48 & & & \\
\hline 3. Smith et al., 1996 & -12 & -1 & 58 & & & \\
\hline 4. D'Esposito et al., 1998 & 0 & 4 & 53 & & & \\
\hline \multicolumn{7}{|l|}{ Non-spatial working memory } \\
\hline a. Paulesu et al., 1993 & -6 & 6 & 56 & & & \\
\hline b. Paulesu et al., 1993 & 4 & 4 & 48 & & & \\
\hline c. Smith et al., 1995 & & & & 1 & 14 & 43 \\
\hline d. Coull et al., 1996 & 2 & 6 & 52 & & & \\
\hline e. Courtney et al., 1996 & & & & 0 & 20 & 36 \\
\hline f. Fiez et al., 1996 & 1 & 9 & 50 & & & \\
\hline g. Klingberg et al., 1996 & 4 & 17 & 46 & & & \\
\hline h. Schumacher et al., 1996 & 26 & 1 & 54 & -1 & 14 & 40 \\
\hline i. Smith et al., 1996 & -1 & 5 & 52 & 6 & 19 & 38 \\
\hline j. Smith et al., 1996 & -6 & 3 & 54 & -3 & 12 & 40 \\
\hline k. Braver et al., 1997 & 13 & 8 & 54 & & & \\
\hline 1. Jonides et al., 1997 & 28 & 1 & 54 & -3 & 8 & 40 \\
\hline m. Klingberg et al., 1997 & -6 & 12 & 50 & & & \\
\hline n. Cohen et al., 1997 & & & & 0 & 16 & 43 \\
\hline o. D'Esposito et al., 1998 & 0 & 4 & 53 & & & \\
\hline
\end{tabular}

man medial motor areas related to simple arm movements, namely the SMA and CMA, both of which are caudal to the VAC plane (for review, see Picard and Strick, 1996). Similarly, the eye movement-related activity observed in the medial part of the superior frontal cortex identified the location of the SEF in each subject. Although we did not monitor eye movements during scanning, previous eye movement measurements outside the scanner demonstrated that subjects comply well with the visually guided saccade task (Petit et al., 1997a). Moreover, the mean location of the SEF in the present study was remarkably consistent with the location of medial superior frontal activation observed during the execution of different types of saccadic eye movements in previous human functional imaging studies [PET: Fox et al. (1985), Paus et al. (1993), Petit et al. (1993, 1996), Anderson et al. (1994), Lang et al. (1994), O’Sullivan et al. (1995), Sweeney et al. (1996); fMRI: Darby et al. (1996), Petit et al. (1997c), Luna et al. (1998)]. These three activations thus identified three distinct, and reliable, functional landmarks that demarcate the motor areas of the medial wall.

\section{The sustained activity during working memory delays in the medial wall}

In the present study, sustained activity during both spatial and face working memory delays was observed in the pre-SMA, anterior to and clearly distinct from the SMA and SEF, and in the caudal-AC, anterior to and clearly distinct from the CMA. A number of previous functional imaging studies have described medial activations during various types of working memory tasks. Table 3 summarizes the Talairach coordinates reported in the frontal part of the medial wall in 14 previous studies that were originally designed to be studies of either spatial or nonspatial visual working memory [PET: Paulesu et al. (1993), Smith et al. (1995), Coull et al. (1996), Courtney et al. (1996), Fiez et al. (1996), Goldberg et al. (1996), Klingberg et al. (1996), Schuma- cher et al. (1996), Smith et al. (1996), Jonides et al. (1997); fMRI: Braver et al. (1997), Cohen et al. (1997), Klingberg et al. (1997), D'Esposito et al. (1998)]. These medial activation foci are plotted on a standard midsagittal view of the human brain (Fig. 4). With only one exception, the foci of activation in the medial superior frontal cortex during these previous spatial and nonspatial working memory tasks are located rostral to the VAC, in the pre-SMA. All foci of activation in the cingulate cortex are located in the most caudal part of the anterior cingulum. Regions demonstrating sustained activity during spatial and face working memory delays in the present study have similar locations in the pre-SMA and caudal-AC (Fig. 4, red circles, red triangles). Note that working memory-related activity is invariably located in the caudal not rostral-AC [also called RCZp in the terminology of Picard and Strick (1996)]. These results suggest that the medial wall activations in previous imaging studies of working memory were caused primarily by sustained activity during memory delays and not by the simple motor components of the tasks. In addition, it is unlikely that the sustained activity during memory delays in the pre-SMA is related to oculomotor control, because the current and previous eye movement studies in humans have found that activity related to visually guided saccades, self-paced saccades, smooth pursuit, and fixation is consistently posterior to the VCA plane (Anderson et al., 1994; Petit et al., 1996, 1997c; Sweeney et al., 1996; Dejardin et al., 1998; Luna et al., 1998) (Fig. 4).

One may ask, therefore, what functional role do these medial wall areas play during working memory delays? Anatomical studies in the monkey indicate that these areas have strong connections to working memory-related areas in dorsolateral prefrontal cortex, suggesting that they constitute an important part of a distributed neural system for working memory (Bates and Goldman-Rakic, 1993). In humans, the pre-SMA is thought to participate in cognitive operations that precede motor output, 
such as the selection of and preparation for a motor response (Marsden et al., 1996; Passingham, 1996; Picard and Strick, 1996; Rizzolatti et al., 1996). The anterior cingulate cortex is thought to be engaged in attention for action, response selection, and cognitively demanding information processing (for review, see Posner, 1994; Posner and Dehaene, 1994; Devinsky et al., 1995). In other words, these medial areas are considered to be part of a cortical system that is involved in decisions to act; that is, what to do and when to do it. The sustained activity during both spatial and face working memory delays was nearly identical in both medial areas. Because the same type of motor response after delays was required during the two working memory tasks, this nonspecific sustained activity may be related to sustained attention during working memory as compared with control delays or to cognitive aspects of the motor output component of the tasks. The extent to which the pre-SMA and caudal-AC areas perform the same attentional or motor preparation function in concert or perform different components of these functions cannot be resolved on the basis of current results.

During the working memory delays in our tasks, subjects did not know what the final motor response would be, but they were prepared to respond with either a right or left button press depending on whether the test stimulus matched a stimulus in the memory set. During control delays, subjects prepared an automatic simple motor response of pressing both buttons. Thus, the sustained activity observed in the present study corresponds to the contrast between readiness to select a motor response as compared with readiness to execute a motor response that was previously selected. Our findings suggest that both the pre-SMA and caudal-AC sustained activity may reflect a higher cognitive level than the simple selection of and preparation for a motor response. It reveals a state of preparedness for selecting a motor response based on the spatial and object information held on-line.

\section{REFERENCES}

Anderson TJ, Jenkins IH, Brooks DJ, Hawken MB, Frackowiak RSJ, Kennard C (1994) Cortical control of saccades and fixation in man: a PET study. Brain 117:1073-1084.

Bates JF, Goldman-Rakic PS (1993) Prefrontal connections of medial motor areas in the rhesus monkey. J Comp Neurol 336:211-228.

Braver TS, Cohen JD, Nystrom LE, Jonides J, Smith EE, Noll DC (1997) A parametric study of prefrontal cortex involvement in human working memory. NeuroImage 5:49-62.

Clark VP, Maisog JM, Haxby JV (1998) fMRI studies of face memory using random stimulus sequences. J Neurophysiol 79:3257-3265.

Cohen JD, Perlstein WM, Braver TS, Nystrom LE, Noll DC, Jonides J, Smith EE (1997) Temporal dynamics of brain activation during a working memory task. Nature 386:604-607.

Coull JT, Frith CD, Frackowiak RSJ, Grasby PM (1996) A frontoparietal network for rapid visual information processing: a PET study of sustained attention and working memory. Neuropsychologia 34:1085-1095.

Courtney SM, Ungerleider LG, Keil K, Haxby JV (1996) Object and spatial visual working memory activate separate neural systems in human cortex. Cereb Cortex 6:39-49.

Courtney SM, Ungerleider LG, Keil K, Haxby JV (1997) Transient and sustained activity in a distributed neural system for human working memory. Nature 386:608-611.

Courtney SM, Petit L, Haxby JV, Ungerleider LG (1998a) The role of prefrontal cortex in working memory: examining the contents of consciousness. Philos Trans R Soc Lond B Biol Sci, in press.

Courtney SM, Petit L, Maisog JM, Ungerleider LG, Haxby JV (1998b) An area specialized for spatial working memory in human frontal cortex. Science 279:1347-1351.

Darby DG, Nobre AC, Thangaraj V, Edelman R, Mesulam MM, Warach S (1996) Cortical activation in the human brain during lateral saccades using EPISTAR functional magnetic resonance imaging. NeuroImage 3:53-62.
Dejardin S, Dubois S, Bodart JM, Schiltz C, Delinte A, Michel C, Roucoux A, Crommelinck M (1998) PET study of human voluntary saccadic eye movements in darkness: effect of task repetition on the activation pattern. Eur J Neurosci 10:2328-2336.

D'Esposito M, Aguirre GK, Zarahn E, Ballard D, Shin RK, Lease J (1998) Functional MRI studies of spatial and non-spatial working memory. Cognit Brain Res, in press.

Devinsky O, Morrell MJ, Vogt BA (1995) Contributions of anterior cingulate cortex to behaviour. Brain 118:279-306.

Fiez JA, Raife EA, Balota DA, Schwarz JP, Raichle ME (1996) A positron emission tomography study of the short-term maintenance of verbal information. J Neurosci 16:808-822.

Fox PT, Fox JM, Raichle ME, Burde RM (1985) The role of cerebral cortex in the generation of voluntary saccades: a positron emission tomographic study. J Neurophysiol 54:348-369.

Friston KJ (1995) Statistical parametric mapping: ontology and current issues. J Cereb Blood Flow Metab 15:361-370.

Friston KJ, Holmes AP, Poline JB, Grasby PJ, Williams SCR, Frackowiak RSJ, Turner R (1995) Analysis of fMRI time-series revisited. NeuroImage 2:45-53.

Goldberg TE, Berman KF, Randolph C, Gold JM, Weinberger DR (1996) Isolating the mnemonic component in spatial delayed response: A controlled PET15O-labeled water regional cerebral blood flow study in normal humans. NeuroImage 3:69-78.

Haxby JV, Parasuraman R, Lalonde F, Abboud H (1993) Superlab: general purpose software for human experimental psychology and psychological testing. Behav Res Methods Instr Comput 25:400-405.

Haxby JV, Maisog JM, Courtney SM (1998) Multiple regression analysis of effects of interest in fMRI time series. In: Mapping and modeling the human brain (Fox PT, Lancaster J, Friston KJ, eds). New York: Wiley, in press.

Jonides J, Schumacher EH, Smith EE, Lauber EJ, Awh E, Minoshima S, Koeppe RA (1997) Verbal working memory load affects regional brain activation as measured by PET. J Cognit Neurosci 9:462-475.

Klingberg T, Kawashima R, Roland PE (1996) Activation of multimodal cortical areas underlies short-term memory. Eur J Neurosci 8:1965-1971.

Klingberg T, O'Sullivan BT, Roland PE (1997) Bilateral activation of fronto-parietal networks by incrementing demand in a working memory task. Cereb Cortex 7:465-471.

Lang W, Petit L, Höllinger P, Pietrzyk U, Tzourio N, Mazoyer B, Berthoz A (1994) A positron emission tomography study of oculomotor imagery. NeuroReport 5:921-924.

Luna B, Thulborn KR, Strojwas MH, McCurtain BJ, Berman RA, Genovese CR, Sweeney JA (1998) Dorsal cortical regions subserving visually-guided saccades in humans: an fMRI study. Cereb Cortex $8: 40-47$.

Marsden CD, Deecke L, Freund HJ, Hallett M, Passingham RE, Shibasaki H, Tanji J, Wiesendanger M (1996) The functions of the supplementary area. In: Advances in neurology: the supplementary sensorimotor area (Lüders HO, ed), pp 477-487. Philadelphia: Lippincott-Raven.

Neter J, Wasserman W, Kutner MH (1990) Applied linear statistical models: regression, analysis of variance, and experimental designs. Homewood, IL: Irwin.

O'Sullivan EP, Jenkins IH, Henderson L, Kennard C, Brooks DJ (1995) The functional anatomy of remembered saccades: a PET study. NeuroReport 6:2141-2144.

Owen AM (1997) The functional organization of working memory processes within human lateral frontal cortex: the contribution of functional neuroimaging. Eur J Neurosci 9:1329-1339.

Passingham RE (1996) Functional specialization of the supplementary motor area in monkeys and humans. In: Advances in neurology: the supplementary sensorimotor area (Lüders HO, ed), pp 105-116. Philadelphia: Lippincott-Raven.

Paulesu E, Frith CD, Frackowiak RSJ (1993) The neural correlates of the verbal component of working memory. Nature 362:342-345.

Paus T, Petrides M, Evans AC, Meyer E (1993) Role of the human anterior cingulate cortex in the control of oculomotor, manual, and speech responses: a positron emission tomography study. J Neurophysiol 70:453-469.

Petit L, Orssaud C, Tzourio N, Salamon G, Mazoyer B, Berthoz A (1993) PET study of voluntary saccadic eye movements in humans: basal ganglia-thalamocortical system and cingulate cortex involvement. J Neurophysiol 69:1009-1017. 
Petit L, Orssaud C, Tzourio N, Crivello F, Berthoz A, Mazoyer B (1996) Functional anatomy of a prelearned sequence of horizontal saccades in man. J Neurosci 16:3714-3726.

Petit L, Clark VP, Ingeholm JE, Haxby JV (1997a) Dissociation of saccade-related and pursuit-related activation in human frontal eye fields as revealed by fMRI. J Neurophysiol 77:3386-3390.

Petit L, Courtney SM, Maisog JM, Ungerleider LG, Haxby JV (1997b) Frontal spatial working memory areas anterior to the frontal and supplementary eye fields studied with fMRI in humans. Soc Neurosci Abstr 23:1679.

Petit L, Ingeholm JE, Clark VP, Courtney SM, Keil T, Maisog JM, Haxby JV (1997c) fMRI study of visually guided saccadic and pursuit eye movements. NeuroImage 5:S248.

Picard N, Strick PL (1996) Motor areas of the medial wall: a review of their location and functional activation. Cereb Cortex 6:342-353.

Posner MI (1994) Attention: the mechanisms of consciousness. Proc Natl Acad Sci USA 91:7398-7403.

Posner MI, Dehaene S (1994) Attentional networks. Trends Neurosci 17:75-79.
Rencher AC (1995) Methods of multivariate analysis. New York: Wiley.

Rizzolatti G, Luppino G, Matelli M (1996) The classic supplementary area is formed by two independent areas. In: Advances in neurology: the supplementary sensorimotor area (Lüders HO, ed), pp 45-56. Philadelphia: Lippincott-Raven.

Schumacher EH, Lauber E, Awh E, Jonides J, Smith EE, Koeppe RA (1996) PET evidence for an amodal verbal working memory system. NeuroImage 3:79-88.

Smith EE, Jonides J, Koeppe RA, Awh E, Schumacher EH, Minoshima S (1995) Spatial versus object working memory: PET investigations. J Cognit Neurosci 7:337-356.

Smith EE, Jonides J, Koeppe RA (1996) Dissociating verbal and spatial working memory using PET. Cereb Cortex 6:11-20.

Sweeney JA, Mintun MA, Kwee S, Wiseman MB, Brown DL, Rosenberg DR, Carl JR (1996) Positron emission tomography study of voluntary saccadic eye movements and spatial working memory. J Neurophysiol 75:454-468.

Talairach J, Tournoux P (1988) Co-planar stereotaxic atlas of the human brain. New York: Thieme. 